Research Article

\title{
High-Efficiency Vibration Isolation for a Three-Phase Power Transformer by a Quasi-Zero-Stiffness Isolator
}

\author{
Hao Cao, ${ }^{1}$ Yaopeng Chang, ${ }^{2}$ Jiaxi Zhou $\left(\mathbb{D},{ }^{2}\right.$ Xuhui Zhao, ${ }^{2}$ Ling Lu, ${ }^{1}$ Fei Chen, ${ }^{1}$ \\ and Xiaowen $\mathrm{Wu}^{1}$ \\ ${ }^{1}$ State Grid Hunan Electric Power Company Limited Research Institute, \\ State Grid Laboratory of Electric Equipment Noise and Vibration Research, Changsha 410007, China \\ ${ }^{2}$ College of Mechanical and Vehicle Engineering, Hunan University, Changsha 410082, China
}

Correspondence should be addressed to Jiaxi Zhou; jxizhou@hnu.edu.cn

Received 14 January 2021; Revised 18 March 2021; Accepted 10 April 2021; Published 20 April 2021

Academic Editor: Jie Yang

Copyright $(2021$ Hao Cao et al. This is an open access article distributed under the Creative Commons Attribution License, which permits unrestricted use, distribution, and reproduction in any medium, provided the original work is properly cited.

\begin{abstract}
The vibrations generated by a three-phase power transformer reduce the comfort of residents and the service life of surrounding equipment. To resolve this tough issue, a quasi-zero-stiffness (QZS) isolator for the transformer is proposed. This paper is devoted to developing a QZS isolator in a simple way for engineering practices. The vertical springs are used to support the heavy weight of the transformer, while the oblique springs are employed to fulfill negative stiffness to neutralize the positive stiffness of the vertical spring. Hence, a combination of the vertical and oblique spring can yield high static but low dynamic stiffness, and the vibration isolation efficiency can be improved substantially. The dynamic analysis for the QZS vibration isolation system is conducted by the harmonic balance method, and the vibration isolation performance is estimated. Finally, the prototype of the QZS isolator is manufactured, and then the vibration isolation performance is tested comparing with the linear isolator under real power loading conditions. The experimental results show that the QZS isolator prominently outperforms the existing linear isolator. This is the first time to devise a QZS isolator for three-phase power transformers with heavy payloads in engineering practices.
\end{abstract}

\section{Introduction}

The three-phase transformer is the critical component of electric power systems, which plays the role of transporting electromagnetic energy from the power station to residential buildings [1-3]. Generally, the radiated noise caused by the transformer presents low-frequency characteristics, which has a destructive effect on the surrounding residents and equipment [3-7]. So far, the sound insulation measures can effectively reduce the propagation of transformer noise in air, but the noise reduction efficiency is limited $[8,9]$. The radiated noise of the transformer is mainly caused by its structural vibration. Therefore, low-frequency vibration control for transformer components is the fundamental way to reduce the low-frequency noise radiation.

To reduce the noise radiation of the transformer, some vibration isolation methods have been developed in recent years [10]. Gu et al. [11] utilized a single-layer-spring device for vibration and noise reduction of the transformer, and the results showed that the device can effectively reduce the noise radiation of the transformer, except for low-frequency vibration. Moreover, the double-layer-spring isolator was used for the transformer by $\mathrm{Wu}$ et al. [12]. Wang et al. [13] utilized a rubber vibration isolator to reduce the noise radiation of the transformer and pointed out that the rubber vibration isolator can effectively decrease the vibration response and thus reduce the external radiation of vibration and noise. Ji et al. [14] applied the adaptive air-spring isolator to attenuate the vibration and noise of the transformer, which exhibited good low-frequency isolation performance and tunability for different working conditions.

Nevertheless, the mentioned vibration isolators cannot achieve low-frequency vibration isolation and ensure the stability of the system at the same time due to heavy payload of the transformer. Therefore, a desirable vibration isolator should possess the characteristics of high-static-low- 
dynamic stiffness to support heavy payload and isolate lowfrequency vibration simultaneously [15-17]. Fortunately, the dynamic stiffness of a QZS isolator can be designed to be zero at the static equilibrium by connecting the negative and positive stiffness mechanism.

In the past few years, various configurations of the QZS isolator [18-22] and nonlinear spring [23, 24] have been proposed and studied. Xu et al. [25] and Wang et al. [26] developed a QZS isolator by utilizing the inclined springs to realize the negative-stiffness mechanism and using the vertical spring to support the payload. Such a mechanism was also used to design QZS isolators by Carrella et al. $[27,28]$. Xu et al. [29] utilized a permanent magnet as a negative-stiffness mechanism in the vertical direction to achieve the QZS isolator. Zhou and Liu [30] and Wu et al. [31] proposed a QZS isolator by adopting a multistory electromagnetic structure and permanent magnets. Based on this mechanism, Shan et al. [32] established a QZS isolator by applying inner and outer magnet rings to provide negative stiffness and neutralize the positive stiffness of a pneumatic spring. Araki et al. [33] applied a newly developed shape memory alloy bar to design a QZS isolator. Jing et al. [34-36] and Sun et al. [37] developed the X-shaped mechanism to achieve the QZS characteristics, which indicated that the structural nonlinearity in the system is helpful for improving the vibration isolation performance. Zhou et al. $[38,39]$ proposed a cam-roller-spring mechanism to realize the QZS isolator. From the above literature studies, it can be found that the QZS vibration isolation method is an encouraging solution for low-frequency vibration isolation. However, the payloads in those literature studies are in the magnitude of $1-10 \mathrm{~kg}$, and the applications of QZS vibration isolation for heavy-duty equipment in engineering practices are rarely reported.

The QZS isolators have a tremendous application prospect in different areas [40, 41]. Le and Ahn [42, 43] proposed a QZS isolator to improve the comfort of the vehicle seat by employing the horizontal and vertical spring. Huang and Liu et al. [44-46] utilized a prestressed bar to accomplish the quasi-zero-stiffness characteristic. Moreover, this mechanism was also used by Zhang et al. [47-49]. Zhou et al. [50] and Wang et al. [51] proposed the mutually repelling permanent magnets and vertical spring to protect the infant from the vibration of the ambulance, but the QZS isolator has never been applied for vibration isolation of the three-phase power transformer yet.

Aiming at the tough issue on low-frequency vibration isolation under heavy payloads for the transformer, a QZS isolator is developed in a simple but effective way by combining vertical springs and oblique springs. The main contribution of this paper is to apply the QZS vibration isolation method in engineering practices. To the authors' best knowledge, this is the first time to devise a QZS isolator for a power transformer. The full-scale prototype of the QZS isolator is developed and fabricated to resolve the tough issue on vibration isolation under heavy payloads. The realworld experiments under high-level power loading $(400-800 \mathrm{kVA})$ and voltage $(10 \mathrm{kV})$ are conducted to evaluate the performance of the proposed QZS isolator and to exhibit the advantage of the QZS isolator over the conventional one.

This paper is organized as follows. In Section 2, the conceptual design of the QZS isolator is conducted, and the stiffness feature is studied to establish the zero-stiffness condition. Moreover, the equation of motion of the QZS vibration isolation system is resolved by the Harmonic Balance Method. In Section 3, the effects of the excitation amplitude and damping ratio on the vibration isolation performance are discussed. Then, the prototype of the QZS isolator is fabricated, and experimental tests are carried out to verify the performance of the QZS isolator under different working conditions in Section 4. Finally, some conclusions are drawn in Section 5.

\section{The Prototype of the QZS Isolators}

2.1. Design Concept. To isolate the vibration of the transformer, a QZS isolator composed of vertical springs $k_{1}$, axial oblique springs $k_{0}$, and a limiting displacement bar, as shown in Figure 1, is proposed. The QZS isolator and transformer are schematically shown in Figure 1(a), where the transformer to be isolated is simplified to a mass $m$, and the QZS isolator is simplified to a nonlinear spring $k_{\mathrm{QZS}}$. The schematic diagram of the QZS isolator without payload is shown in Figure 1(b), where the oblique and vertical spring is of original length. Figure 1(c) shows the static equilibrium position, all springs are compressed, the oblique springs lie along the horizontal direction, and the mass $m$ is supported by the vertical spring totally at this time. The physical model is shown in Figure 1(d). For the oblique springs, the ends are constrained on the upper and lower plate, respectively, by using hinge joints, which act as the negative-stiffness mechanism. And the vertical springs are fixed onto the lower plate.

2.2. Analysis of Combined Stiffness. As shown in Figure 1(a), when the transformer is subjected to an external force $f(t)$, the oblique springs open an angle $\theta$, and the mass undergoes a displacement $y$ with respect to the horizontal direction and the static equilibrium position, respectively.

The restoring force $f_{r}$ can be given by

$$
f_{r}(y)=k_{1} y-2 k_{0} y\left(\frac{L}{\sqrt{\mathfrak{R}^{2}+y^{2}}}-1\right),
$$

where $\mathfrak{R}$ represents the compressed length at the static equilibrium position and $L$ denotes the original length of the oblique spring.

Equation (1) can be written in the nondimensional form as

$$
\widehat{f}_{r}=\hat{y}-2 \Im \hat{y}\left(\frac{1}{\sqrt{\widehat{\Re}^{2}+\widehat{y}^{2}}}-1\right),
$$

where $\widehat{y}=y / L, \widehat{\mathfrak{R}}=\mathfrak{R} / L, \widehat{f}_{r}=f_{r} / k_{1} L$, and $\mathfrak{I}=k_{0} / k_{1}$.

Differentiating equation (2) with respect to $\hat{y}$, the stiffness $\widehat{k}_{\mathrm{QZS}}$ can be given: 


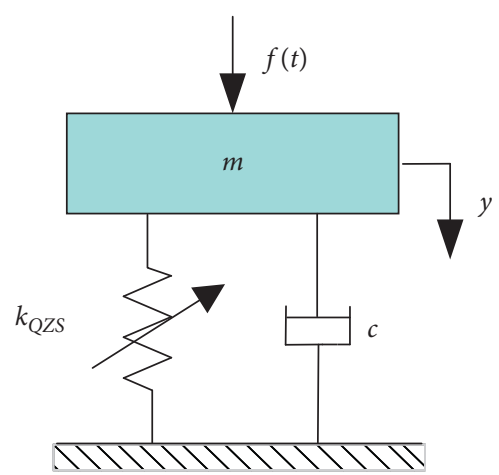

(a)

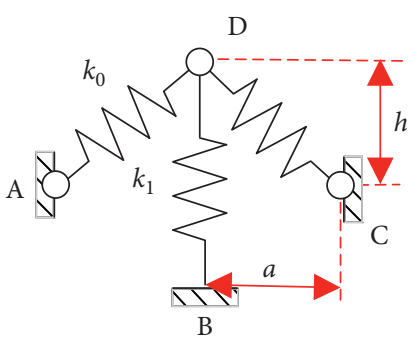

(b)

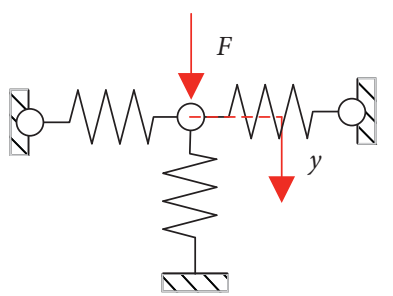

(c)

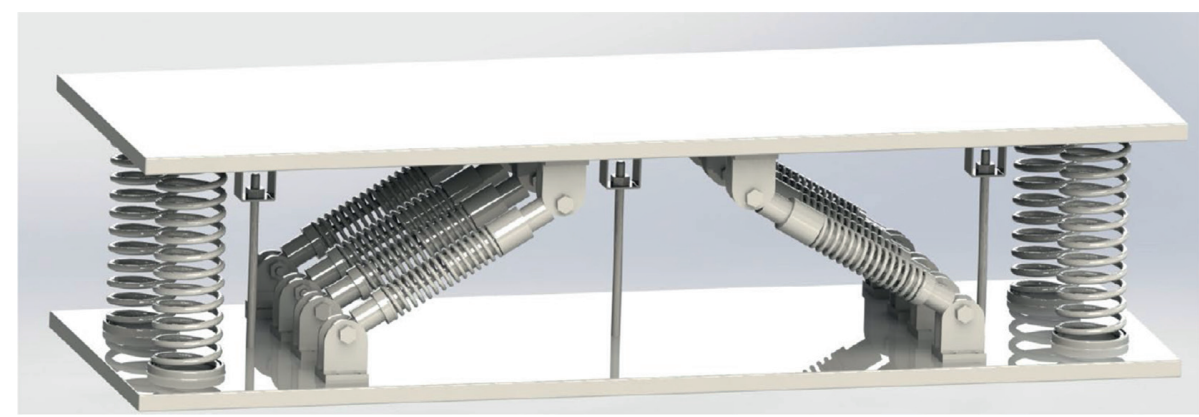

(d)

FIgURE 1: The model of the QZS isolator: (a) schematic diagram, (b) no loading, (c) static equilibrium position with loading $F$, where $F$ is equal to $m g$, and (d) physical model.

$$
\widehat{k}_{\mathrm{QZS}}(y)=1-2 \mathfrak{\Im}\left(\frac{\widehat{\mathfrak{R}}^{2}}{\sqrt{\left(\widehat{\mathfrak{R}}^{2}+\hat{y}^{2}\right)^{3}}}-1\right) \text {. }
$$

If the stiffness $\widehat{k}_{\mathrm{QZS}}=0$ when $\hat{y}=0$, the stiffness ratio $\Im_{\text {QZS }}$ can be defined as

$$
\Im_{\mathrm{QZS}}=\frac{\widehat{\Re}}{2(1-\widehat{\Re})} .
$$

Therefore, the condition of zero stiffness is that the positive and negative stiffness, the compressed length, and the original length should satisfy equation (4).

To make sure that when the mass of the transformer is loading on the QZS isolator, the oblique spring is horizontal, the vertical spring $k_{1}$ has to satisfy the condition

$$
F=k_{1} h=m g,
$$

where $h$ is the vertical height of the oblique spring from its original length to its equilibrium position, $m$ is the mass of the transformer, and $g$ is the acceleration of gravity. by

Therefore, the stiffness of the vertical spring can be given

$$
k_{1}=\frac{m g}{h} .
$$

Through the above analysis and practical requirements, the physical prototype is developed, and its parameters are tabulated in Table 1.
TABle 1: The physical parameters.

\begin{tabular}{lccc}
\hline Parameter & Value & Parameter & Value \\
\hline$k_{1}$ & $1.12 \times 10^{5}(\mathrm{~N} / \mathrm{m})$ & $m$ & $1800(\mathrm{~kg})$ \\
$k_{0}$ & $3.02 \times 10^{5}(\mathrm{~N} / \mathrm{m})$ & $h$ & $160(\mathrm{~mm})$ \\
$L$ & $300(\mathrm{~mm})$ & $\Re$ & $253(\mathrm{~mm})$ \\
\hline
\end{tabular}

2.3. Dynamics of the QZS VIS. To analyze the QZS vibration isolator system (VIS) theoretically, the restoring force of the QZS VIS is fitted as a cubic polynomial with respect to $y$. The restoring force is shown in Figure 2(a), which appears horizontal near the equilibrium position. The stiffness is depicted in Figure 2(b), which shows a remarkable lowstiffness feature and even zero stiffness $(\hat{y}=0)$.

The fitted polynomial of restoring force $f_{r}(y)$ is defined as

$$
f_{r}(y)=k_{n 1} y+k_{n 3} y^{3},
$$

where $k_{n 1}=871.4(\mathrm{~N} / \mathrm{m})$ and $k_{n 3}=6.515 \times 10^{7}\left(\mathrm{~N} / \mathrm{m}^{3}\right)$.

For the QZS VIS in Figure 1(a), the force excitation is $f(t)=f_{0} \sin \omega t$, in which $f_{0}$ and $\omega$ are the amplitude and frequency, respectively. The dynamic equation can be given by

$$
m \ddot{y}+c \dot{y}+k_{n 1} y+k_{n 3} y^{3}=f_{0} \sin \omega t .
$$

The nondimensional equation can be rewritten by

$$
\ddot{\hat{y}}+2 \xi \dot{\hat{y}}+\alpha \hat{y}+\gamma \widehat{y}^{3}=\bar{f}_{0} \sin \omega \tau,
$$




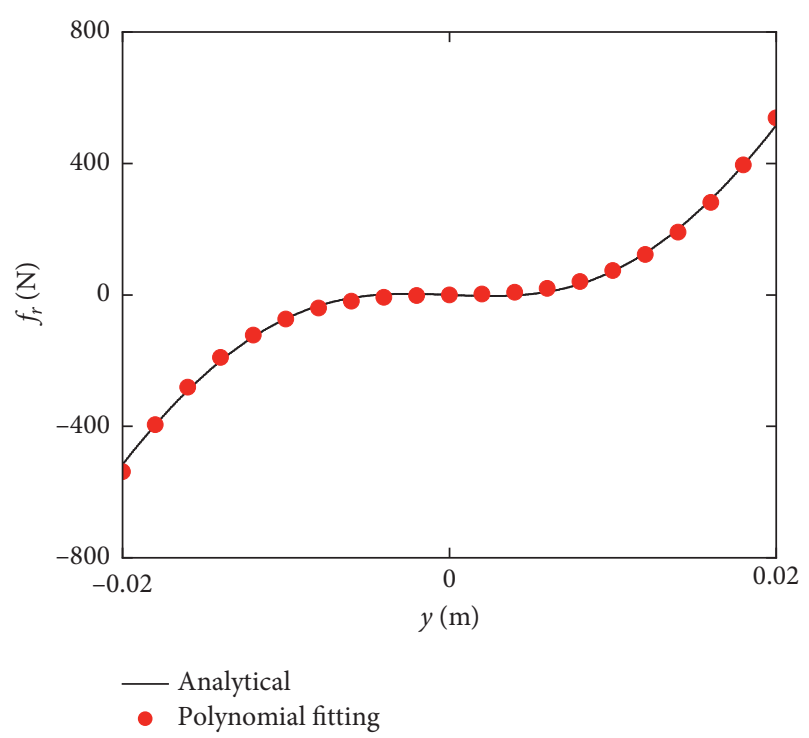

(a)

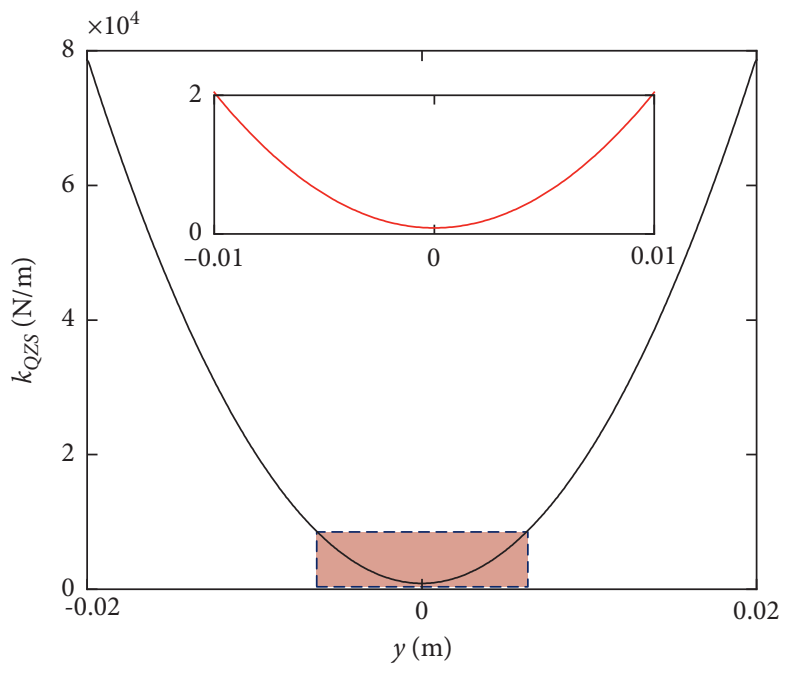

(b)

Figure 2: (a) Restoring force. (b) Stiffness.

where $\tau=\omega_{0} t, \quad \Phi=\omega / \omega_{0}, \quad \omega_{0}=k_{1} / m, \quad \bar{f}_{0}=f_{0} / k_{1} L$, $\xi=c / 2 m \omega_{0}, \alpha=k_{n 1} / k_{1}$, and $\gamma=k_{n 3} L^{2} / k_{1}$.

Assume that the response $\hat{y}$ is defined as

$$
\widehat{y}=\widehat{Y} \sin (\bowtie \tau+\varphi)
$$

where $\hat{Y}$ is the displacement amplitude and $\varphi$ is the phase.

By using the harmonic balance method (HBM), the response equation can be given by

$$
\left(\alpha \widehat{Y}+\frac{3}{4} \gamma \widehat{Y}^{3}-\omega^{2} \widehat{Y}\right)^{2}+(2 \xi \omega \widehat{Y})^{2}=\bar{f}_{0}^{2} .
$$
by

The force transmitted through the QZS isolator is given

$$
\tilde{f}_{T}=2 \xi \dot{\hat{y}}+\alpha \hat{y}+\gamma \widehat{y}^{3} .
$$

The magnitude of the transmitted force at an excitation frequency is given by

$$
\hat{f}_{T}=\sqrt{(2 \xi \bowtie \widehat{Y})^{2}+\left(\frac{3}{4} \gamma \widehat{Y}^{3}+\alpha \widehat{Y}\right)^{2}} .
$$

Thus, the force transmissibility $T_{\mathrm{b}}$, defined as the ratio of equation (13) to equation (12), can be yielded:

$$
T_{b}=\frac{\sqrt{(2 \xi \omega \widehat{Y})^{2}+\left((3 / 4) \gamma \widehat{Y}^{3}+\alpha \widehat{Y}\right)^{2}}}{\bar{f}_{0}} .
$$

\section{Parametric Analysis}

The excitation induced by the transformer generally contains many harmonic components. The excitation amplitude is related to the level of power loading. Therefore, the theoretical analysis on the force transmissibility is necessary. It should be noted that the parameters of the QZS isolator are designed according to the weight and space sizes of the real transformer, which are employed for the analysis of force transmissibility. Unfortunately, it is quite difficult to determine the force excitation acting on the vibration isolation system and the damping caused by possible contact and friction. Therefore, the effects of the force amplitude and damping on the vibration isolation performance are discussed.

3.1. Influence of Excitation Amplitude. The above analyses from equation (14) show that $T_{b}$ can be influenced by $\xi$ and $\bar{f}_{0}$. Figure (3) presents the effect of the parameter $\bar{f}_{0}$ on $T_{b}$ and jumping-down frequency. The force transmissibility $T_{b}$ under the excitations with different amplitudes is shown in Figure 3(a). It can be seen that, with the increase of $\bar{f}_{0}$, the amplitude-frequency curve is bent more and more noticeable, and the peak force transmissibility is increased. Obviously, the nonlinearity becomes more significant with the increase in excitation amplitude. The jump-down frequency is depicted in Figure 3(b), which implies that the jumpingdown frequency can also be increased with the increase in excitation amplitude $\bar{f}_{0}$. Therefore, the smaller the excitation amplitude is, the lower the jumping-down frequency is and thus the wider the frequency band for effective vibration isolation is.

3.2. Influence of Damping Ratio. The effect of $\xi$ on the force transmissibility and jumping-down frequency is shown in Figure 4. For a small damping ratio, for example, $\xi=0.05$, the resonance curve is largely bent to the right-hand side. When $\xi=0.25$, the resonance peak is reduced, and the jumping phenomena are about to disappear. Therefore, it can be inferred that if the damping ratio continues to increase, the resonance peak will completely vanish. In addition, it can be seen from Figure 3(b) that the jumping- 


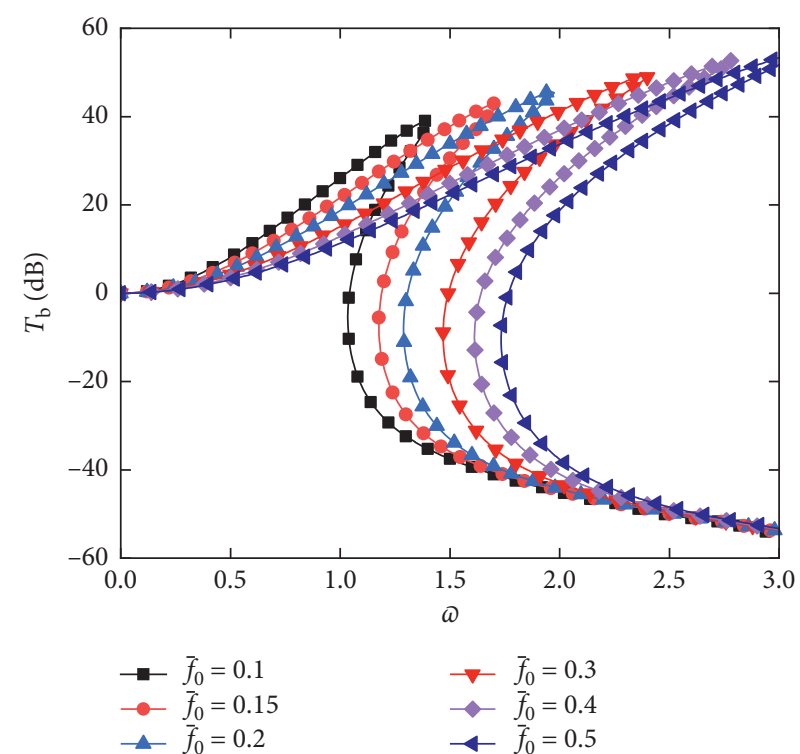

(a)

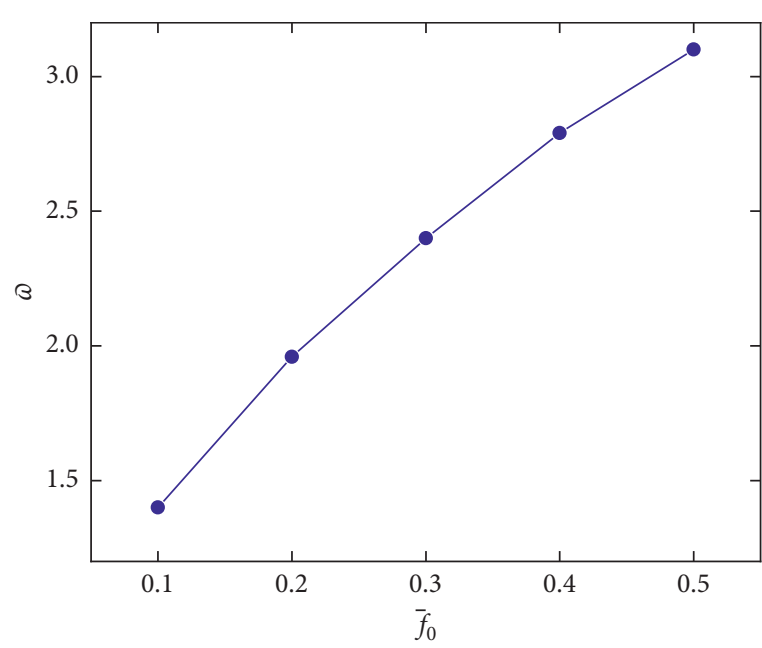

(b)

Figure 3: The excitation amplitude of the QZS VIS: (a) force transmissibility; (b) jumping-down frequency.

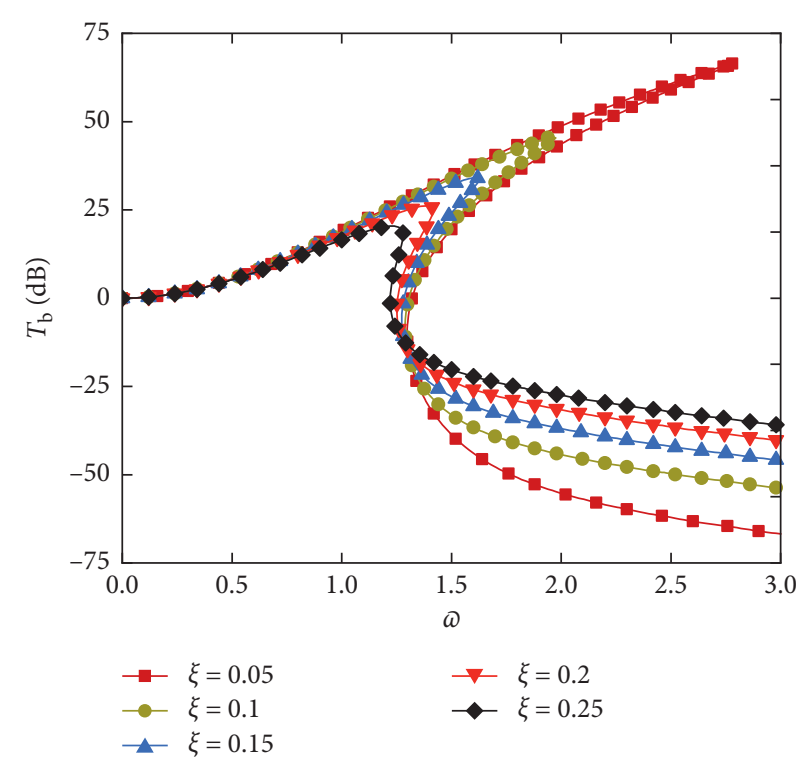

(a)

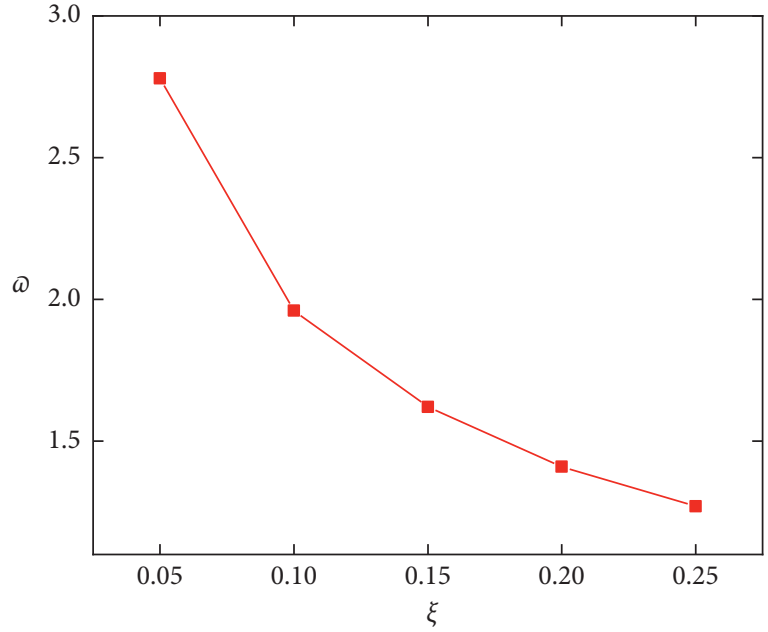

(b)

FIgURE 4: The damping ratio of the QZS VIS: (a) force transmissibility; (b) jumping-down frequency.

down frequency decreases with the increase in the damping ratio.

\section{Experimental Verification}

To verify the vibration isolation performance of the QZS isolator, the prototype of the QZS isolator is fabricated, as shown in Figure 5(a). The experimental apparatus and installation are set up, as shown in Figure 6. A large number of experimental tests under real power loading conditions are carried out to evaluate the performance of the QZS isolator, which is also compared with the conventional linear isolator to show its advantages of low-frequency vibration isolation.

4.1. Static Feature. The QZS isolator of the transformer consists of four vertical springs, eight oblique springs, upper and lower plates, and hinges, as shown in Figure 5(a). The relationship between the restoring force and displacement is measured by the tensile and compression testing machine. The loading acts on the top plate of the QZS isolator, and displacement loading is input starting from $-20 \mathrm{~mm}$ until to 


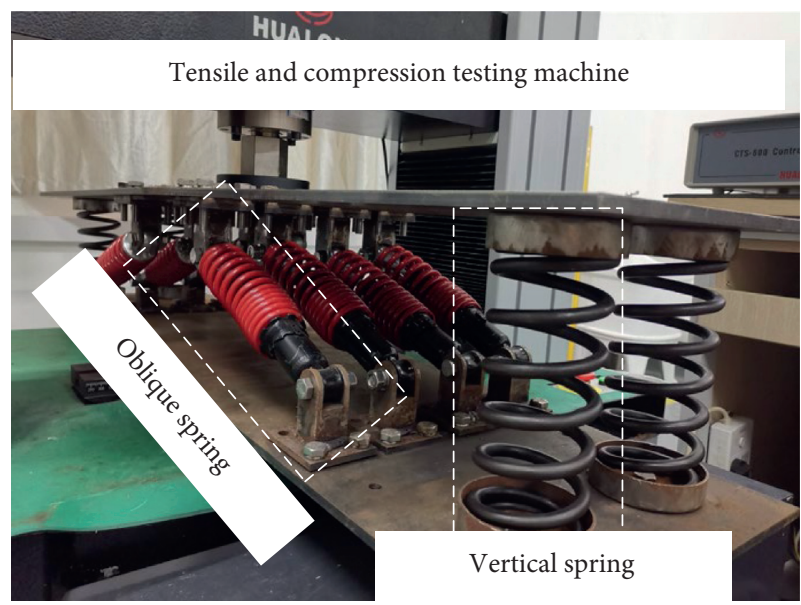

(a)

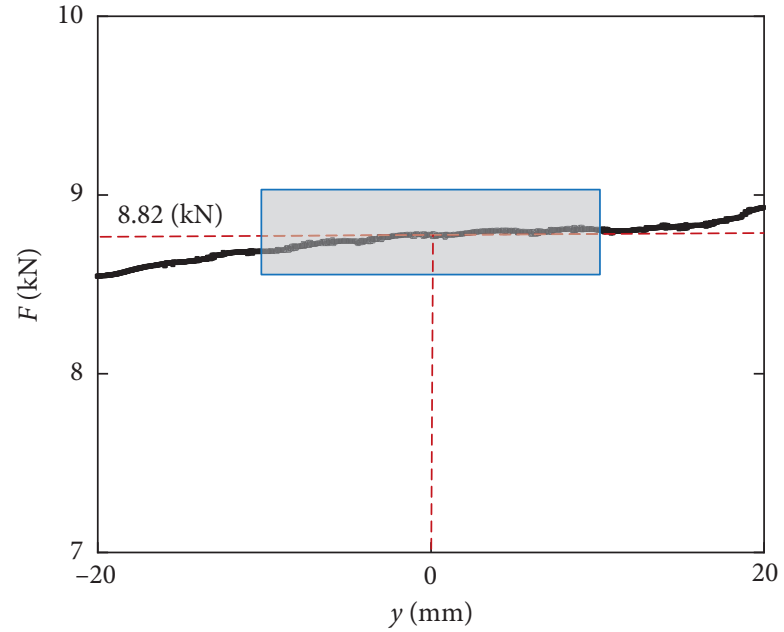

(b)

FIGURE 5: Static test: (a) prototype; (b) experimental measured restoring force curves.

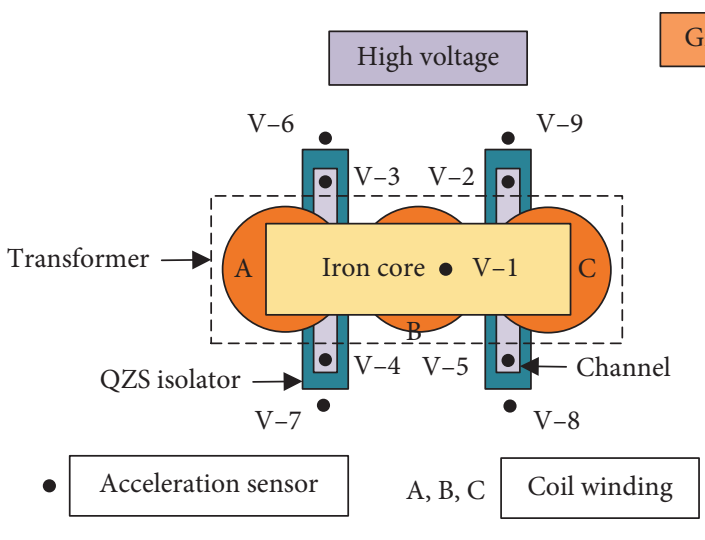

(a)

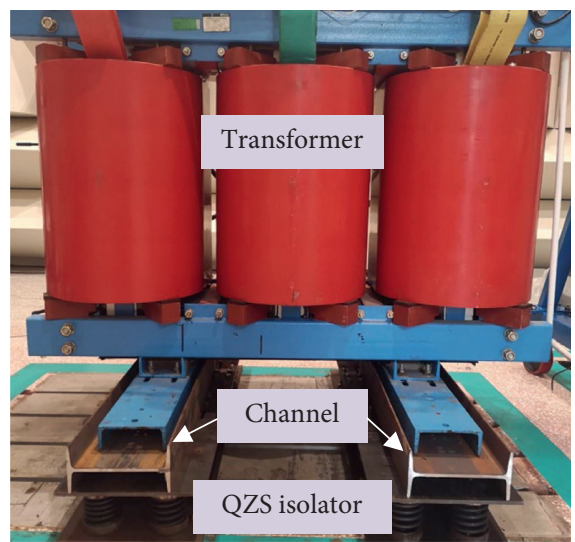

(b)

FIGURE 6: Dynamics experiment: (a) installation diagram of the QZS isolator and sensors; (b) experimental prototype.

$20 \mathrm{~mm}$. The measured relationship between the restoring force and displacement is presented in Figure 5(b). Obviously, in the displacement range from $-10 \mathrm{~mm}$ to $10 \mathrm{~mm}$ (a rectangle box enclosed by the blue solid line), the curves are nearly flat, which indicates quasi-zero stiffness. Note that when $y=0$, the VIS arrives at the equilibrium position. At this time, the loading force $F$ is equal to $8.82 \mathrm{kN}$, which implies that when the payload supported by each QZS isolator is $900 \mathrm{~kg}$, the system can achieve the characteristic of zero stiffness around the static equilibrium position.

4.2. Vibration Isolation Performance. The experimental setup of the QZS isolator is shown in Figure 6. The sampling frequency of the signal acquisition card is $65536 \mathrm{~Hz}$, and the position of the acceleration sensor is shown in the black dot in Figure 6(a). Note that V-1 is installed on the iron core, $\mathrm{V}-2, \mathrm{~V}-3, \mathrm{~V}-4$, and $\mathrm{V}-5$ are installed on the channel steel fixed on the top plate of the QZS isolator, and V-6, V-7, V-8, and V-9 are installed on the base. The transformer is placed on the QZS isolator, and the channel steel is arranged between them to ensure that the QZS isolator is evenly stressed. The layout of the experimental test device is shown in Figure 6(b).

The experiments for three cases are carried out, namely, no isolator, linear isolator, and QZS isolator. The base vibration responses are measured for different isolators for given working conditions of the transformer. The black short-dash line represents the case of no isolator, the red solid line represents the linear isolator, and the blue dash line represents the QZS isolator. Note that the dominated frequency of the transformer is mainly half or double frequency of $100 \mathrm{~Hz}$. The acceleration response is presented as $T_{a}=20 \log \left(\mathrm{Re} / I_{a}\right)$ in $\mathrm{dB}$. The symbol of Re and $I_{a}$ represents the base acceleration and unit acceleration, respectively.

The power loading and voltage of the transformer are $400 \mathrm{kVA}$ and $10 \mathrm{kV}$, respectively, and the base vibration response in the range of $0 \sim 1000 \mathrm{~Hz}$ is shown in Figure 7. It 


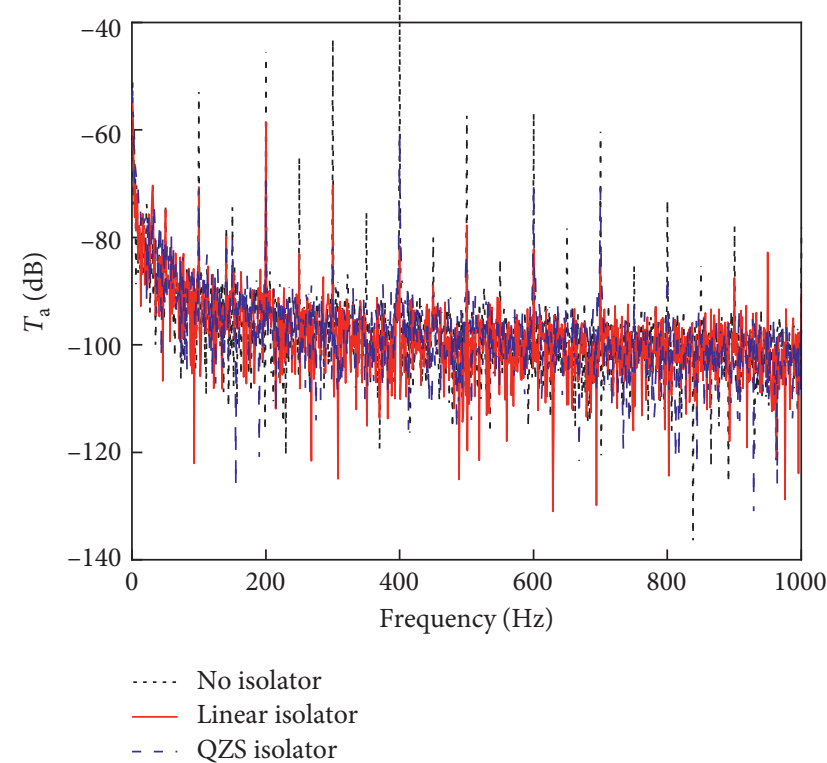

(a)

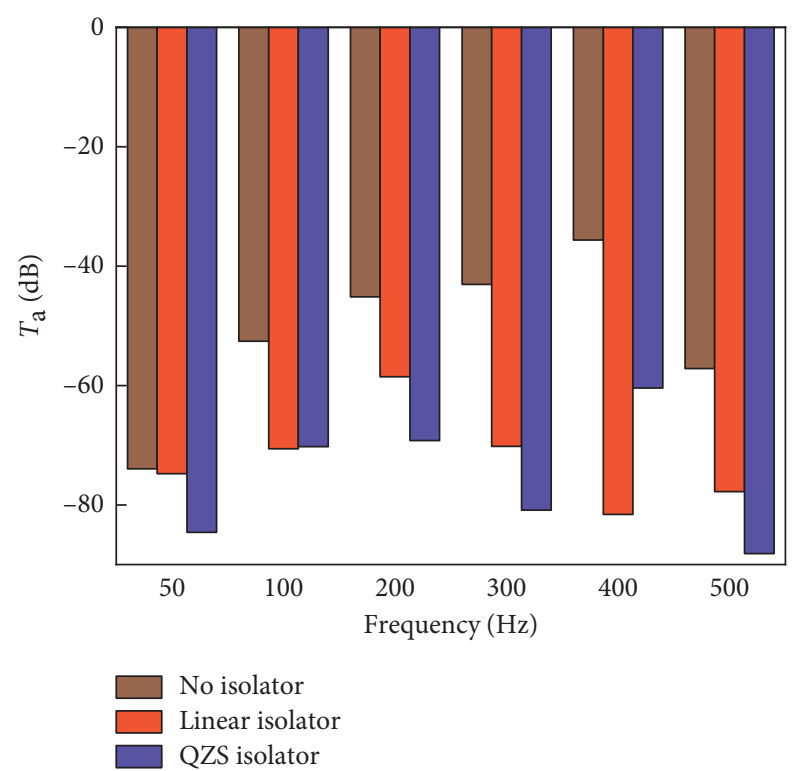

(b)

FIGURE 7: The ground vibration response when the load and voltage of the transformer are $400 \mathrm{kVA}$ and $10 \mathrm{kV}$, respectively.

can be clearly seen from Figure 7(a) that the performance of the QZS vibration isolator is obviously better than that of the linear isolator and no isolator at most dominated frequencies. Figure 7(b) shows that the QZS isolator can effectively improve the vibration isolation performance at the dominated frequencies except $100 \mathrm{~Hz}$ and $400 \mathrm{~Hz}$. Especially, at $200 \mathrm{~Hz}$ and $300 \mathrm{~Hz}$, the acceleration response of the base can be reduced by $11 \mathrm{~dB}$ and $10 \mathrm{~dB}$ compared with the linear isolator, respectively. However, the vibration isolation performance of the QZS isolator at $400 \mathrm{~Hz}$ has obvious deterioration compared with other dominated frequencies.

It should be noted that the QZS isolator is a kind of nonlinear vibration isolator, and its vibration isolator performance would be impacted by several factors, e.g., excitation amplitude. As shown in Figure $7(\mathrm{a})$, at $400 \mathrm{~Hz}$, the acceleration response of the base is larger than that at other dominated frequencies. Generally, the large-amplitude excitation would degrade the vibration isolator performance [38]. Consequently, the QZS isolator has no advantage over the linear one at $400 \mathrm{~Hz}$.

In order to exhibit the repeatability of the test, each test is repeated three times. The performance obtained from these three repeated tests is depicted in Figure 8 when the power loading and voltage of the transformer are $400 \mathrm{kVA}$ and $10 \mathrm{kV}$, respectively. It can be seen from Figure 8 that the performances in repeated tests are in good agreement, for all the three cases of no isolator, linear isolator, and QZS isolator. The differences of performance among the repeated tests are quite small, as shown in Figure 8(b), which implies the experimental tests have good repeatability, and thus, the experimental results are correct and reliable.

When the power loading and voltage of the transformer are $600 \mathrm{kVA}$ and $10 \mathrm{kV}$, respectively, the base vibration response is shown in Figure 9. In Figure 9(a), the acceleration response of the base $T_{a}$ for the system with the QZS isolator is notably smaller than that of the linear isolator and no isolator. That is to say, the performance of the QZS vibration isolator is generally better than that of the linear isolator. However, at several special frequencies, such as $400 \mathrm{~Hz}$ and $500 \mathrm{~Hz}$, the vibration isolation performance of the QZS isolator would not be better than that of the linear isolator, but the QZS isolator is still better than the case without any isolator, which implies that the QZS isolator always performs the function of vibration isolation in such a case. Obviously, as the power loading is increased, the excitation amplitude becomes larger definitely. Under such a loading condition, the performance of the QZS isolator is reduced compared with that in the case of $400 \mathrm{kVA}$ (Figure 7). Especially, at $400 \mathrm{~Hz}$ and $500 \mathrm{~Hz}$, the advantage of the QZS isolator over the linear isolator would disappear. However, the acceleration response of the base for the QZS vibration isolation system is lower than the case of no isolator, which means that the QZS isolator is still workable at such two frequencies.

Furthermore, when the power loading is increased to $800 \mathrm{kVA}$ and the voltage remains unchanged $(10 \mathrm{kV})$ (i.e., full-load condition), the response is shown in Figure 10. Under such a condition, the power transformer would undergo large-amplitude oscillations, and the nonlinearity of the QZS isolator would become stronger. Therefore, the vibration isolation performance of the QZS isolator degrades further as the power loading increases. Especially, at $50 \mathrm{~Hz}$, the performance of the QZS isolator is worse than that of the linear isolator but better than that of no isolator. At $100 \mathrm{~Hz}$, the acceleration response of the QZS vibration isolation system is somewhat higher than the case of no isolator, which implies that the acceleration is amplified through the isolator. However, even in such an extremely harsh condition, the vibration isolation performance is noticeably 

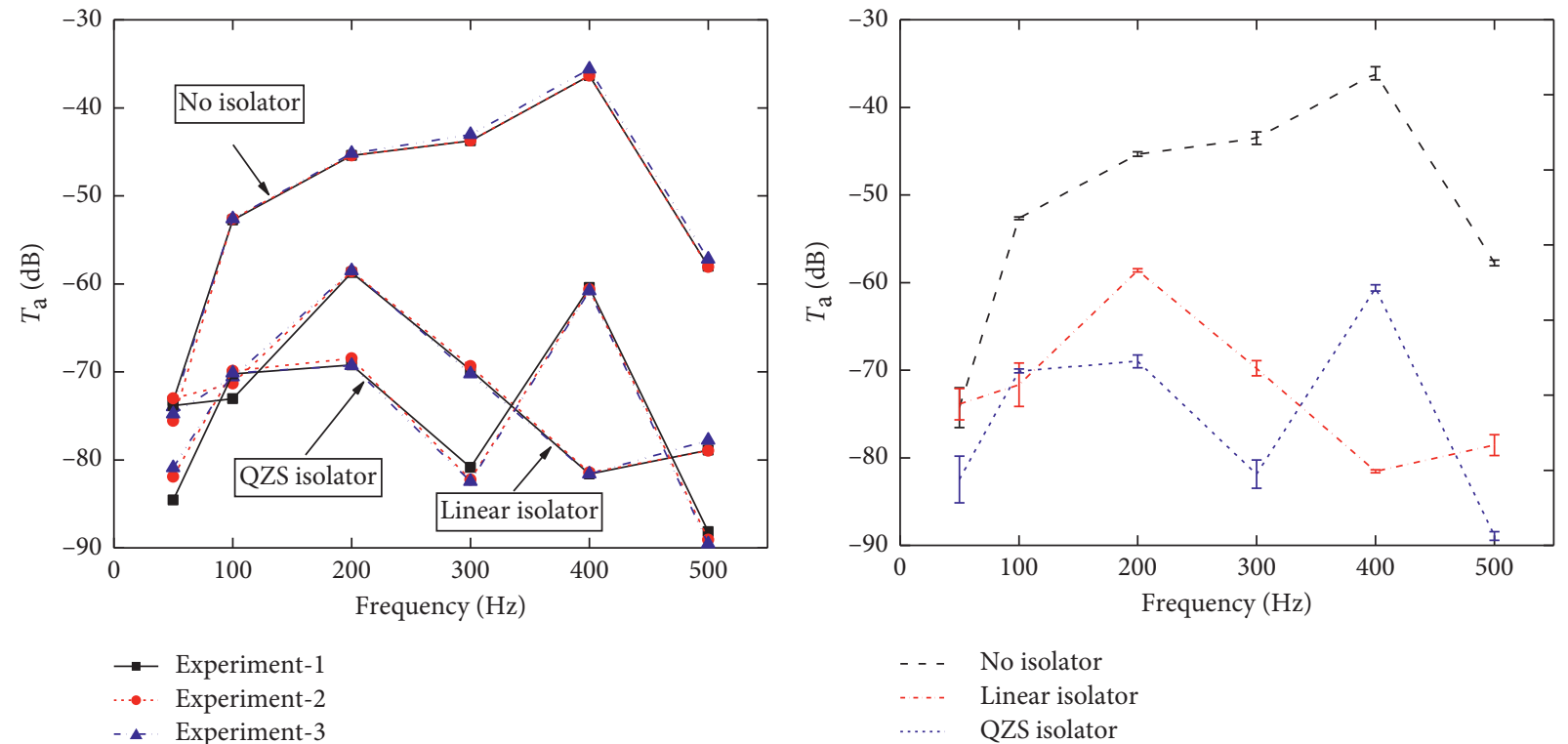

(a)

(b)

FIGURE 8: The ground vibration response (a) and error bar (b) in three experiments when the load and voltage of the transformer are $400 \mathrm{kVA}$ and $10 \mathrm{kV}$, respectively.

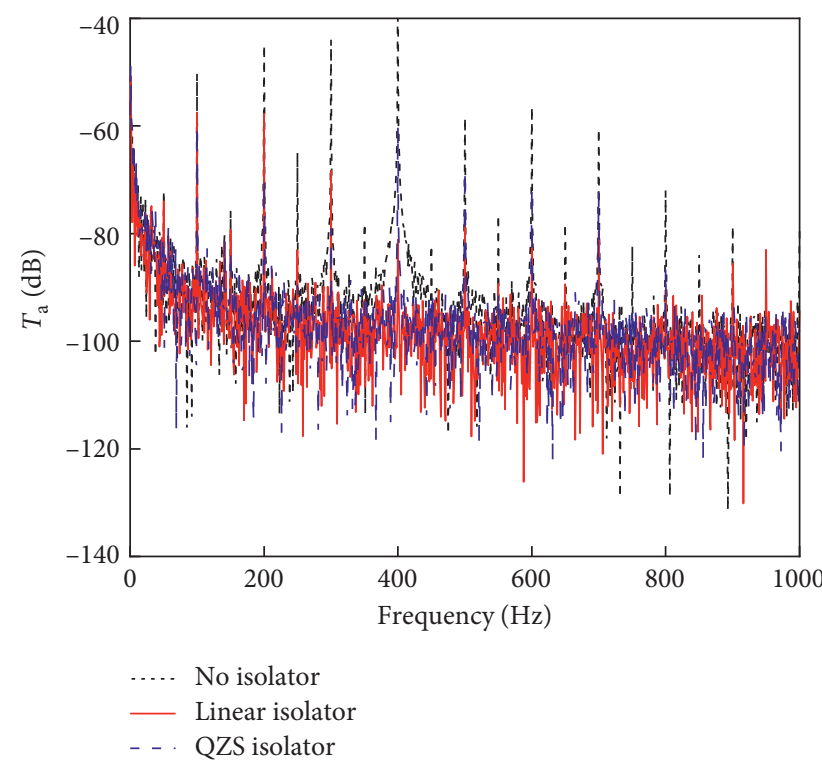

(a)

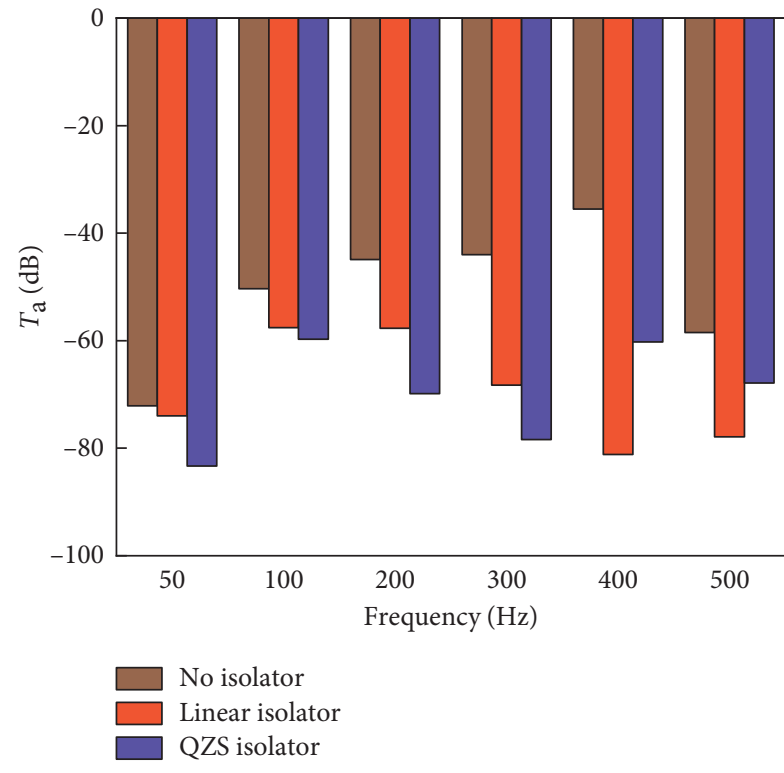

(b)

FIGURE 9: The ground vibration response when the load and voltage of the transformer are $600 \mathrm{kVA}$ and $10 \mathrm{kV}$, respectively. 


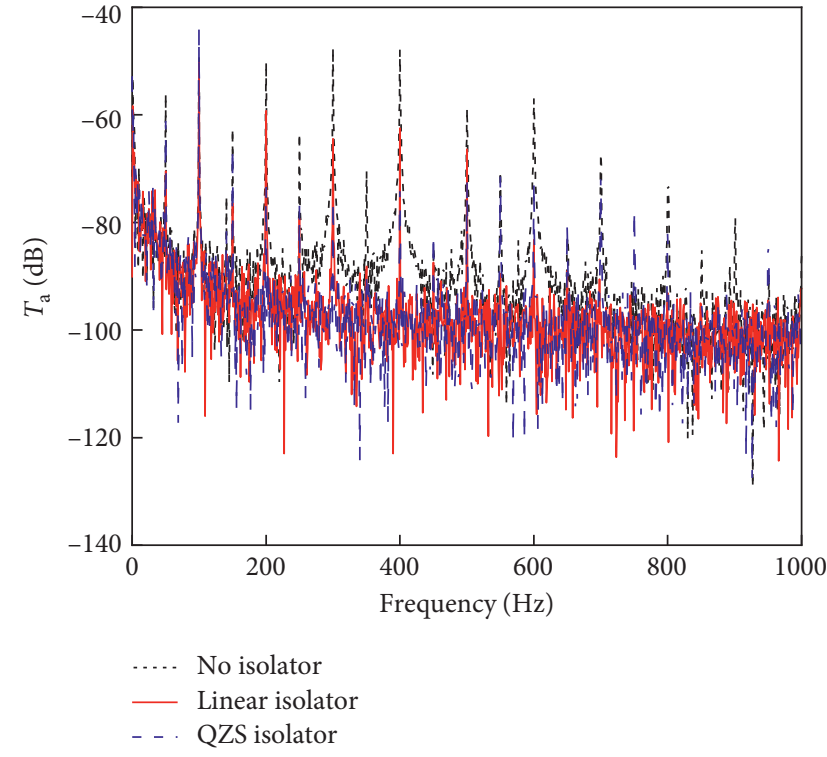

(a)

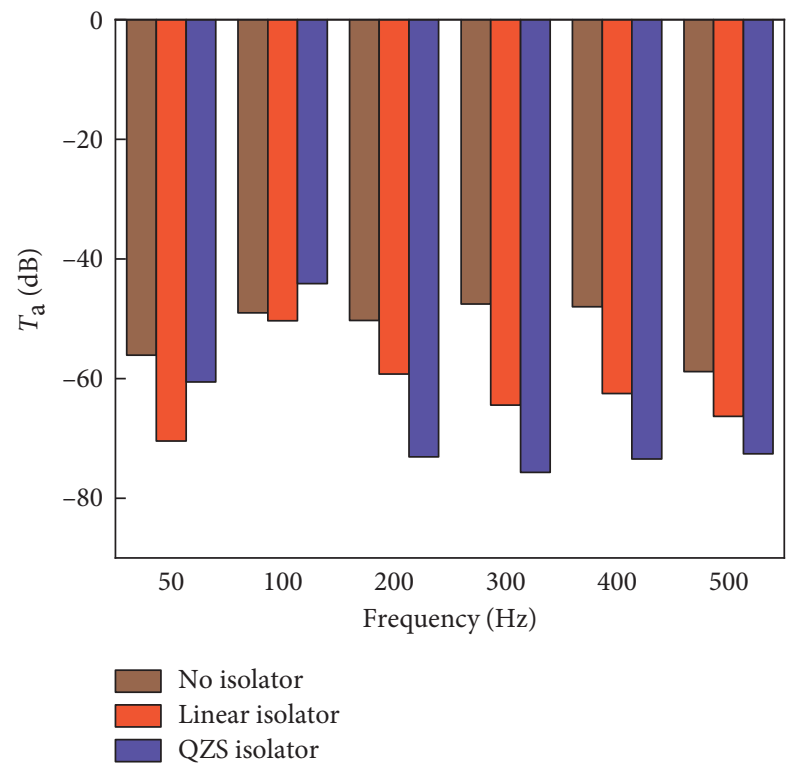

(b)

FIGURE 10: The ground vibration response when the load and voltage of the transformer are $800 \mathrm{kVA}$ and $10 \mathrm{kV}$, respectively.

improved by the QZS isolator at high frequencies, such as 200, 300, 400, and $500 \mathrm{~Hz}$, compared to the linear isolator and no isolator, as shown in Figure 10(b).

\section{Conclusions}

In this work, a quasi-zero-stiffness (QZS) isolator is proposed by combining oblique and vertical springs to improve the vibration isolation performance for the threephase power transformer under heavy payloads. The vertical springs are considered to meet the requirement on weight capability. The axial compressible oblique springs are designed to realize negative stiffness to neutralize positive stiffness and thus to neutralize the positive stiffness of the vertical spring. Both static and dynamic characteristics are investigated, and the influence of the system parameters on the transmissibility is discussed. The analytical results show that both jumping-down frequency and peak transmissibility increase with the increase in the excitation amplitude. Moreover, the jumping-down frequency may disappear, and the transmissibility peak is significantly suppressed as the damping ratio increases.

Most importantly, the prototype of the QZS isolator is fabricated, and its performances under real power loading conditions are evaluated by experiments. The results indicate that the QZS isolator has desired high-static-low-dynamic stiffness and good vibration isolation performance under different power loading conditions. A remarkable advantage of the QZS isolator over the conventional linear one can also be observed by comparative experiments. It is the first time to devise a QZS isolator for the power transformer, and thus, this paper should be a valuable contribution to the community of vibration isolation, especially for engineering applications.

\section{Data Availability}

The data used to support the findings of this study are available from the corresponding author upon request.

\section{Conflicts of Interest}

The authors declare that they have no conflicts of interest.

\section{Authors' Contributions}

Yaopeng Chang and Hao Cao contributed equally to this work and should be considered co-first authors. Yaopeng Chang, Jiaxi Zhou, and Hao Cao conceptualized the study and reviewed and edited the article. Hao Cao, Xuhui Zhao, and Ling $\mathrm{Lu}$ were responsible for data curation. Yaopeng Chang and Fei Chen performed formal analysis. Jiaxi Zhou contributed to funding acquisition. Hao Cao, Yaopeng Chang, Xuhui Zhao, Fei Chen, and Xiaowen Wu investigated the study. Yaopeng Chang and Jiaxi Zhou developed the methodology. Xuhui Zhao contributed to software. Jiaxi Zhou, Ling Lu, and Xiaowen $\mathrm{Wu}$ supervised the study. Yaopeng Chang and Hao Cao wrote the original draft.

\section{Acknowledgments}

This research work was supported by the National Natural Science Foundation of China (11972152), the Natural Science Foundation of Hunan Province (2020JJ4208), and Science and Technology Project of State Grid Power Company (5016A019000P).

\section{References}

[1] S. Ahmad, R. Mat Tahar, F. Muhammad-Sukki, A. B. Munir, and R. Abdul Rahim, "Application of system dynamics 
approach in electricity sector modelling: a review," Renewable and Sustainable Energy Reviews, vol. 56, pp. 29-37, 2016.

[2] I. Dincer, "Renewable energy and sustainable development: a crucial review," Renewable and Sustainable Energy Reviews, vol. 4, no. 2, pp. 157-175, 2000.

[3] C. Gonzalez-Garcia and J. Pleite, "Transformer model in wide frequency bandwidth for power electronics systems," Advances in Power Electronics, vol. 2013, Article ID 249146, 8 pages, 2013.

[4] B. G. Churcher and A. J. King, "The limitation of transformer noise," Journal of the Institution of Electrical Engineers, vol. 87, no. 527, pp. 539-554, 1940.

[5] R. Girgis, M. Bernesjö, S. Thomas, J. Anger, D. Chu, and H. Moore, "Development of ultra-low noise transformer technology," in Proceedings of the 2011 IEEE Power and Energy Society General Meeting, IEEE, pp. 1-8, Piscataway, NJ, USA, 2011.

[6] C. Bartoletti, M. Desiderio, D. DiCarlo et al., "Vibro-acoustic techniques to diagnose power transformers," IEEE Transactions on Power Delivery, vol. 19, no. 1, pp. 221-229, 2004.

[7] G.-Q. Di, X.-X. Zhou, and X.-W. Chen, “Annoyance response to low frequency noise with tonal components: a case study on transformer noise," Applied Acoustics, vol. 91, pp. 40-46, 2015.

[8] X. Sun, J. Xu, F. Wang, and L. Cheng, "Design and experiment of nonlinear absorber for equal-peak and de-nonlinearity," Journal of Sound and Vibration, vol. 449, pp. 274-299, 2019.

[9] Y. Zheng, X. Zhang, Y. Luo, B. Yan, and C. Ma, "Design and experiment of a high-static-low-dynamic stiffness isolator using a negative stiffness magnetic spring," Journal of Sound and Vibration, vol. 360, pp. 31-52, 2016.

[10] Y. C. Liu, Y. L. Luo, P. H. Wang, J. K. Nie, and G. X. Dong, "Nonresonant response of quasi-zero stiffness platform for power transformer," Chinese Journal of Applied Mechanics, vol. 37, pp. 161-167+397, 2020, (In Chinese).

[11] S. L. Gu, X. Tong, S. L. He, G. Cheng, and Z. Yin, "Study and design of vibration and noise reduction device for transformed," Mech. Eng. Autom.vol. 210, no. 5, pp. 121-123, 2018, (In Chinese).

[12] Q. Wu, F. Q. Gao, and A. X. Zou, "The principle, design and experiment of a double-layer isolation device applied for indoor transformers," Journal of Sichuan University (Natural Science Edition), vol. 26, pp. 323-326, 2006, (In Chinese).

[13] G. K. Wang, Q. Fang, W. J. Lu, J. S. Chen, and L. Lin, "Current situation of application of damping vibration isolation material and device in substation," Smart Grid, vol. 4, pp. 4-9, 2016, (In Chinese).

[14] Z. Y. Ji, H. Zhang, Y. S. Yang, and X. M. Wen, "An engineering practice of transformers structure noise reduction by the air," Spring. Pollut. Control Technol.vol. 24, pp. 61-64, 2011, (In Chinese).

[15] P. V. Trung, K.-R. Kim, and H.-J. Ahn, "A nonlinear control of an QZS isolator with flexures based on a lyapunov function," International Journal of Precision Engineering and Manufacturing, vol. 14, no. 6, pp. 919-924, 2013.

[16] K. Wang, J. Zhou, H. Ouyang, L. Cheng, and D. Xu, "A semiactive metamaterial beam with electromagnetic quasi-zerostiffness resonators for ultralow-frequency band gap tuning," International Journal of Mechanical Sciences, vol. 176, Article ID 105548, 2020.

[17] C. Cheng, S. Li, Y. Wang, and X. Jiang, "On the analysis of a high-static-low-dynamic stiffness vibration isolator with time-delayed cubic displacement feedback," Journal of Sound and Vibration, vol. 378, pp. 76-91, 2016.

[18] G. Zhu, J. Liu, Q. Cao, Y. Cheng, Z. Lu, and Z. Zhu, "A two degree of freedom stable quasi-zero stiffness prototype and its applications in aseismic engineering," Science China Technological Sciences, vol. 63, no. 3, pp. 496-505, 2020.

[19] H. Ding, Z.-Q. Lu, and L.-Q. Chen, "Nonlinear isolation of transverse vibration of pre-pressure beams," Journal of Sound and Vibration, vol. 442, pp. 738-751, 2019.

[20] Z. Lu, M. Brennan, H. Ding, and L. Chen, "High-static-lowdynamic-stiffness vibration isolation enhanced by damping nonlinearity," Science China Technological Sciences, vol. 62, no. 7, pp. 1103-1110, 2019.

[21] J. Yang, Y. P. Xiong, and J. T. Xing, “Dynamics and power flow behaviour of a nonlinear vibration isolation system with a negative stiffness mechanism," Journal of Sound and Vibration, vol. 332, no. 1, pp. 167-183, 2013.

[22] K. Wang, J. Zhou, D. Xu, and H. Ouyang, "Tunable lowfrequency torsional-wave band gaps in a meta-shaft," Journal of Physics D: Applied Physics, vol. 52, no. 5, p. 055104, 2019.

[23] F. Ding, Q. Li, C. Jiang et al., "Event-triggered control for nonlinear leaf spring hydraulic actuator suspension system with valve predictive management," Information Sciences, vol. 551, pp. 184-204, 2021.

[24] J. Zhang, F. Ding, B. Zhang, C. Jiang, H. Du, and B. Li, “An effective projection-based nonlinear adaptive control strategy for heavy vehicle suspension with hysteretic leaf spring," Nonlinear Dynamics, vol. 100, no. 1, pp. 451-473, 2020.

[25] D. Xu, Y. Zhang, J. Zhou, and J. Lou, "On the analytical and experimental assessment of the performance of a quasi-zerostiffness isolator," Journal of Vibration and Control, vol. 20, no. 15 , pp. 2314-2325, 2014.

[26] K. Wang, J. Zhou, D. Xu, and H. Ouyang, "Lower band gaps of longitudinal wave in a one-dimensional periodic rod by exploiting geometrical nonlinearity," Mechanical Systems and Signal Processing, vol. 124, pp. 664-678, 2019.

[27] A. Carrella, M. J. Brennan, and T. P. Waters, "Static analysis of a passive vibration isolator with quasi-zero-stiffness characteristic," Journal of Sound and Vibration, vol. 301, no. 3-5, pp. 678-689, 2007.

[28] A. Carrella, M. J. Brennan, I. Kovacic, and T. P. Waters, "On the force transmissibility of a vibration isolator with quasizero-stiffness," Journal of Sound and Vibration, vol. 322, no. 45, pp. 707-717, 2009.

[29] D. Xu, Q. Yu, J. Zhou, and S. R. Bishop, "Theoretical and experimental analyses of a nonlinear magnetic vibration isolator with quasi-zero-stiffness characteristic," Journal of Sound and Vibration, vol. 332, no. 14, pp. 3377-3389, 2013.

[30] N. Zhou and K. Liu, "A tunable high-static-low-dynamic stiffness vibration isolator," Journal of Sound and Vibration, vol. 329, no. 9, pp. 1254-1273, 2010.

[31] W. Wu, X. Chen, and Y. Shan, "Analysis and experiment of a vibration isolator using a novel magnetic spring with negative stiffness," Journal of Sound and Vibration, vol. 333, no. 13, pp. 2958-2970, 2014.

[32] Y. Shan, W. Wu, and X. Chen, "Design of a miniaturized pneumatic vibration isolator with high-static-low-dynamic stiffness," Journal of Vibration and Acoustics, vol. 137, no. 4, 2015.

[33] Y. Araki, K. Kimura, T. Asai, T. Masui, T. Omori, and R. Kainuma, "Integrated mechanical and material design of quasi-zero-stiffness vibration isolator with superelastic $\mathrm{Cu}$ Al-Mn shape memory alloy bars," Journal of Sound and Vibration, vol. 358, pp. 74-83, 2015.

[34] Y. Wang and X. Jing, "Nonlinear stiffness and dynamical response characteristics of an asymmetric X-shaped structure," Mechanical Systems and Signal Processing, vol. 125, pp. 142-169, 2019. 
[35] G. Jiang, X. Jing, and Y. Guo, "A novel bio-inspired multijoint anti-vibration structure and its nonlinear HSLDS properties," Mechanical Systems and Signal Processing, vol. 138, Article ID 106552, 2020.

[36] J. Bian and X. Jing, "Superior nonlinear passive damping characteristics of the bio-inspired limb-like or X-shaped structure," Mechanical Systems and Signal Processing, vol. 125, pp. 21-51, 2019.

[37] X. Sun, X. Jing, J. Xu, and L. Cheng, "Vibration isolation via a scissor-like structured platform," Journal of Sound and Vibration, vol. 333, no. 9, pp. 2404-2420, 2014.

[38] J. Zhou, X. Wang, D. Xu, and S. Bishop, "Nonlinear dynamic characteristics of a quasi-zero stiffness vibration isolator with cam-roller-spring mechanisms," Journal of Sound and Vibration, vol. 346, pp. 53-69, 2015.

[39] J. Zhou, D. Xu, and S. Bishop, "A torsion quasi-zero stiffness vibration isolator," Journal of Sound and Vibration, vol. 338, pp. 121-133, 2015.

[40] Y. Chang, J. Zhou, K. Wang, and D. Xu, "A quasi-zerostiffness dynamic vibration absorber," Journal of Sound and Vibration, vol. 494, Article ID 115859, 2021.

[41] C. Cai, J. Zhou, L. Wu, K. Wang, D. Xu, and H. Ouyang, "Design and numerical validation of quasi-zero-stiffness metamaterials for very low-frequency band gaps," Composite Structures, vol. 236, Article ID 111862, 2020.

[42] T. D. Le and K. K. Ahn, "A vibration isolation system in low frequency excitation region using negative stiffness structure for vehicle seat," Journal of Sound and Vibration, vol. 330, no. 26, pp. 6311-6335, 2011.

[43] T. D. Le and K. K. Ahn, "Experimental investigation of a vibration isolation system using negative stiffness structure," International Journal of Mechanical Sciences, vol. 70, pp. 99-112, 2013.

[44] X. Liu, X. Huang, and H. Hua, "On the characteristics of a quasi-zero stiffness isolator using Euler buckled beam as negative stiffness corrector," Journal of Sound and Vibration, vol. 332, no. 14, pp. 3359-3376, 2013

[45] X. Huang, Y. Chen, H. Hua, X. Liu, and Z. Zhang, "Shock isolation performance of a nonlinear isolator using Euler buckled beam as negative stiffness corrector: theoretical and experimental study," Journal of Sound and Vibration, vol. 345, pp. 178-196, 2015.

[46] X. Huang, X. Liu, J. Sun, Z. Zhang, and H. Hua, "Vibration isolation characteristics of a nonlinear isolator using euler buckled beam as negative stiffness corrector: a theoretical and experimental study," Journal of Sound and Vibration, vol. 333, no. 4, pp. 1132-1148, 2014.

[47] Y. Zheng, X. Zhang, Y. Luo, Y. Zhang, and S. Xie, "Analytical study of a quasi-zero stiffness coupling using a torsion magnetic spring with negative stiffness," Mechanical Systems and Signal Processing, vol. 100, pp. 135-151, 2018.

[48] G. Dong, X. Zhang, S. Xie, B. Yan, and Y. Luo, "Simulated and experimental studies on a high-static-low-dynamic stiffness isolator using magnetic negative stiffness spring," Mechanical Systems and Signal Processing, vol. 86, pp. 188-203, 2017.

[49] G. Dong, X. Zhang, Y. Luo, Y. Zhang, and S. Xie, "Analytical study of the low frequency multi-direction isolator with highstatic-low-dynamic stiffness struts and spatial pendulum," Mechanical Systems and Signal Processing, vol. 110, pp. 521539, 2018.

[50] J. Zhou, K. Wang, D. Xu, H. Ouyang, and Y. Fu, "Vibration isolation in neonatal transport by using a quasi-zero-stiffness isolator," Journal of Vibration and Control, vol. 24, no. 15, pp. 3278-3291, 2017.
[51] Q. Wang, J. Zhou, D. Xu, and H. Ouyang, "Design and experimental investigation of ultra-low frequency vibration isolation during neonatal transport," Mechanical Systems and Signal Processing, vol. 139, Article ID 106633, 2020. 